\title{
Spatial evaluation of the multiple benefits of sustainable drainage systems
}

1 Malcolm Morgan MEng, PhD

Research Fellow, Sustainability Research Institute (SRI), School of Earth and Environment, Leeds University, Leeds, UK
2 Richard Fenner BSc (Hons), PhD, CEng, MICE, FCIWEM Reader in Engineering Sustainability, Centre for Sustainable Development, Department of Engineering, University of Cambridge, Cambridge, UK (corresponding author: raf37@cam.ac.uk)
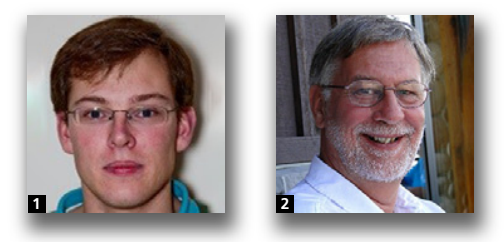

Traditional approaches to understanding the multiple benefits of sustainable drainage systems often rely on value transfer. This converts each benefit into a monetary value, which can then be compared with the cost of the project. The approach, while well-developed, is limited because it does not systematically incorporate the spatial nature of the benefits. This paper discusses the development of an alternative way of evaluating and comparing benefits, allowing spatial distribution and local context and circumstances to be taken into consideration. The suggested approach is to create a score for each benefit category, which is normalised against a defined initial condition state on a scale of 0 to 10. This approach allows a direct comparison of the relative magnitude of benefits for a given location and provides a clear understanding of how and to whom multiple benefits accrue. The approach allows a singular significant benefit to be compared against many minor benefits. It can also easily be modified to reflect local preferences by weighting each benefit category appropriately. The method is demonstrated by three case studies in Newcastle, UK.

\begin{tabular}{ll}
\multicolumn{2}{l}{ Notation } \\
$B$ & benefit uplift \\
$b$ & benefit score \\
$b_{\text {aft }}$ & reference benefit \\
$b_{\text {bef }}$ & before benefit \\
$C_{\text {aft }}$ & after characteristic \\
$C_{\text {bef }}$ & before characteristic \\
$C_{\text {max }}$ & Maximum characteristic value \\
$C_{\min }$ & minimum characteristic value \\
$E$ & benefit effectiveness \\
$P$ & potential benefit
\end{tabular}

\section{Introduction}

Modern urban environments are impacted by stormwater runoff, exacerbated by increasing frequencies of more severe weather events. Traditional solutions carry the water rapidly 'away' in pipes and channels, so it accumulates further down an urban catchment, potentially causing more serious flooding problems elsewhere. Managing this runoff locally at its source has been the preferred policy of drainage engineers since the 1990s. Sustainable drainage systems (Suds) often use naturally vegetated surfaces and local storage ponds and are promoted as viable 'blue-green' alternatives to the more traditional 'grey' concrete conveyance systems. However, the uptake of Suds in many cities remains slow and robust justification for their adoption is often required. This can be achieved by modelling hydraulic performance to demonstrate their effectiveness at mitigating urban flooding (Ahilan et al., 2014) while also acknowledging that such blue-green infrastructure (BGI) can deliver an extensive range of other benefits and add to the greening and regeneration of cities.

The multiple benefits of Suds have been widely reported (e.g. Ashley et al, 2013; Benedict and McMahon, 2012; Ellis, 2013; Hoang and Fenner, 2016; Jose et al., 2015; USEPA, 2013). Ciria (2013) suggest that the range of benefits can be considered in terms of the following.

(a) Direct economic value, for example increased land value due to flood reduction and more productive fisheries and so on due to pollution control (e.g. Penning Rowsell et al., 2005).

(b) Added aesthetic and amenity value, for example additional green infrastructure (e.g. Natural England, 2009).

(c) Added environmental or ecosystem value due to less stress on environmental systems or the creation of new biodiversity in urban areas; many of these benefits relate to ecosystem services (Sukhdev et al., 2010).

(d) Social benefits, which tend to be diverse and less easily quantifiable (Cabinet Office and New Economics Foundation, 2012).

Generally, the benefits arising from Suds that incorporate 'green' infrastructure (GI) can extend to enhancing urban sustainability through improving community resilience, liveability 
and balancing human needs with environmental enhancement (Ciria, 2013). Designing these kinds of assets to achieve such multi-functionality requires decision support tools to evaluate both Suds/GI primary functions and their wider benefits. Various tools and methodologies have been proposed, such as life-cycle assessment (Casal-Campos et al., 2013; Flynn and Traver, 2013), scenario planning (Hilde and Paterson, 2014), expert knowledge (Kopperoinen et al., 2014), and modelling using tools such as i-tree and EnviroAtlas (Kim et al., 2015; Pickard et al., 2015).

Many practitioners seek to monetise the disparate range of multiple benefits that can accrue for incorporation in conventional cost-benefit balance sheets, and tools have recently been developed that attempt this. For example, Ciria's Benefits of Suds Tool (BeST) methodology provides a structured approach to evaluating a wide range of benefits, often based on the drainage system performance overall. It follows a simple structure that begins with a screening and qualitative assessment to identify the benefits worthy of further evaluation. It then provides support to help quantify and monetise each benefit. On completion of the evaluation, the tool provides a series of graphs and charts to present the benefits based on ecosystem services and triple bottom line criteria (Ciria, 2015).

However, Spengenberg and Settele (2010) cautioned that monetised results are dependent on both context and method, can fail to reflect complex interactions between benefits and, where value transfer is adopted, large uncertainties can accrue. Value transfer is a process where values identified by primary research in one study area are used to infer values in the area of interest. Natural England (2013) reviewed a number of GI valuation tools that purport to provide an estimate of a range of benefits in monetary terms and also noted that value transfer can be complex and should only be undertaken with guidance from experienced practitioners.

The UK Water Partnership (UKWP, 2015) called for more holistic thinking that provides a framework for looking at whole ecosystems and valuing the services they provide, in particular to examine the spatial scale of interactions within natural and urban environments so that the constraints, limitations and the people involved in supplying/receiving ecosystem services and benefits can be understood. Techniques are emerging that represent the spatial distribution of ecosystem services by normalising each benefit value to a common scale and aggregating these spatially in a geographic information system (GIS) platform (Dobbs et al., 2014; Lauf et al., 2014; Turner et al., 2014). Jayasooriya and $\mathrm{Ng}$ (2014) reviewed 20 modelling tools for managing urban flooding and the economics of GI practices and noted the trend for recent tools to include a GIS interface, calling for more tools to incorporate the range of ecosystem services and social benefits that GI practices can provide.
Demuzere et al. (2014) recognised the trade-offs in which a positive impact of adopting GI-based flood measures can compromise other functions, such as generating larger carbon footprints due to more frequent maintenance activities, or green areas fostering pest and nuisance species with potential associated risks to human health. In reviewing studies on ecosystem structures designed for human wellbeing, von Döhren and Haase (2015) also demonstrated psychological, human health, economic and ecological dis-benefits relating to asset maintenance, human allergies and safety concerns.

The methodology described and demonstrated in this paper emphasises the following key points (Hoang et al., 2016).

(a) The general impacts of Suds and associated BGI may include both benefits and dis-benefits, and these are context-dependent.

(b) Trade-offs may occur between different benefit categories for a range of installation types, and these in turn are also influenced by specific local contexts and background environmental conditions.

(c) Many of the benefits are incremental and need to be assessed in relation to the level of similar services that pre-existed in each specific location and the rate they develop over time.

(d) It can be difficult to compare directly across non-commensurate benefit categories to establish the relative contribution that each can deliver in specific local circumstances, individual site characteristics and against the preferences of local communities.

(e) Benefits can accrue to different stakeholder groups other than the asset owner and these are distributed across spatial scales from local to regional to global.

Due to the need for the evaluation to be spatial in nature, the use of a GIS as the basis of the evaluation was chosen. Furthermore, as this paper seeks to demonstrate that the proposed method could be practically applied, it was decided that a set of tools capable of performing the evaluation should be created. Therefore, a toolbox for ArcGIS 10·3 was produced using the approach described in this paper and is published on the Blue-Green Cities website (BGC, 2017). This paper presents new concepts of benefit profile and benefit intensity and their application is demonstrated in three locations in Newcastle, UK.

\section{Benefit evaluation process}

\subsection{Normalisation}

Normalisation allows different benefits to be compared on a common scale. Traditional approaches such as cost-benefit analysis effectively normalise different benefits onto a single monetary scale. While this aids comparison between benefits and allows the benefits to be compared with the costs, it is often difficult to put a financial value on some benefits. The method 
described here normalises each benefit category on a scale from 0 to 10 , where 0 is defined as the worst case and 10 as the best case for that benefit. Previous researchers have used normalisation in ecosystem services approaches, scaling linearly as a proportion of the maximum observed values at the particular study site (Lauf et al., 2014).

The approach proposed here is based on the absolute best and worst achievable scores for the benefit and these do not change depending on the context; the normalised results from different locations are thus comparable. At this stage, there is no relative weighting between benefit categories, although it is possible to weight benefits at the end of the process (e.g. to reflect stakeholder preferences of each benefit category) and this is discussed later in the paper. This is done in order to be able first to directly compare the straightforward magnitude of each benefit on a common basis before then addressing the relative importance each benefit has in specific circumstances (which fundamentally reflects preference information and judgement).

\subsection{Best and worst cases}

The definition of best and worst cases requires some care. If the best and worst cases are placed too close together, part of the range of possible values will be lost and the evaluation will be less informative. Similarly, if they are spaced too far apart changes will appear diluted as they will only occur in a small range of benefit scores, rather than taking advantage of the full $0-10$ score range.

Noise pollution provides a good example of how to select best and worst cases. In theory, the least amount of noise possible is absolute silence whereas a jet engine at $30 \mathrm{~m}$ is around $140 \mathrm{~dB}$ (and the loudest sound possible is frequently reported as $194 \mathrm{~dB}$ ). A more pragmatic approach is to say that nobody is bothered by noises below $40 \mathrm{~dB}$ and everybody dislikes noise above $100 \mathrm{~dB}$ (Pennig and Schady (2014)). This more pragmatic range has the benefit of being evidence based and strikes a balance between too wide and too narrow a scale.

\subsection{Benefit curve}

The passage from the best case to the worst case may not be linear. Indeed, many natural systems are highly non-linear, contain tipping points, or have optimal values. The benefit curve allows the normalisation process to consider these nonlinear systems where necessary. The benefit curve dictates the normalisation process, translating a physical characteristic into a benefit score. Each characteristic should have its own benefit curve, and the derivation of these curves should be based on the best available evidence.

Figure 1 shows a hypothetical benefit curve. The positive gradient indicates a desirable characteristic (more is better) and the increasing gradient indicates that the majority of the benefit is derived close to the maximum value. Figure 1 also shows how a change in a characteristic is translated into benefit uplift $(B)$, which relates the benefit to an initial condition state in location-specific circumstances. The total benefit uplift score is calculated by summing the benefit uplift for each individual grid cell in the analysis. It is possible to aggregate the results across the whole study area or interrogate the results across multiple areas. It is also possible to separate areas with

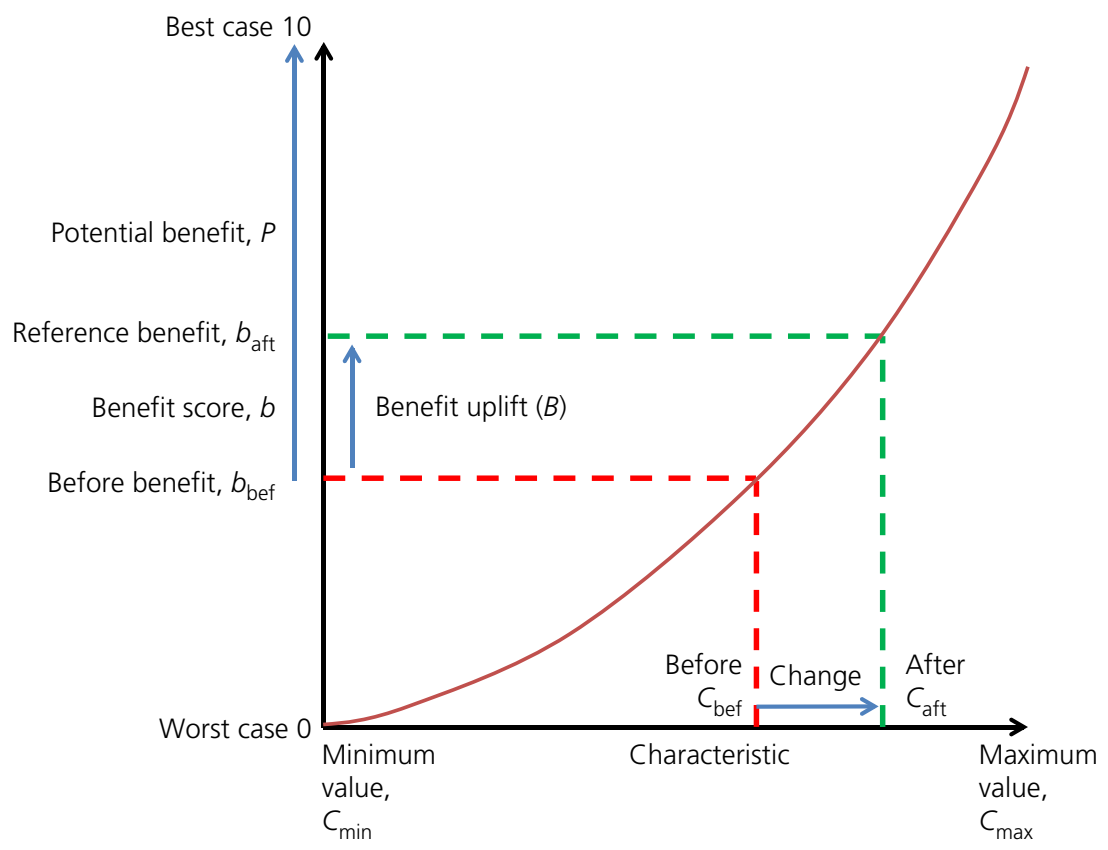

Figure 1. Hypothetical benefit curve 
a positive benefit from areas with a negative benefit and also to analyse those areas independently.

\section{$2.4 \quad$ Benefit intensity}

Benefits are likely to vary spatially; through a combination of measurement and modelling, it is possible to map characteristics of interest. Indeed, for many characteristics, such as flooding or pollution, maps and tools may already exist. To assess the benefit uplift of a proposed Suds scheme it is necessary to produce a map for each characteristic both with and without the Suds scheme.

By applying the benefit curve to the characteristic maps, it is possible to derive the spatial distribution of the benefit uplift, called the benefit intensity, by performing the calculation over a network of grid squares.

It is important to note that the grid square resolution at which the benefit intensity is calculated has a significant effect on the total benefit score. A higher spatial resolution will provide more individual benefit scores; thus, when they are added together, the total benefit score will be higher. For comparison purposes it is therefore necessary that a uniform spatial resolution for every benefit evaluation is used during a benefit analysis and that the spatial resolution is stated on any results derived from a benefit analysis.

This issue can be addressed by resampling the benefit intensity maps to a common spatial resolution before calculating the total benefit, but this should not be confused with increasing the detail of the benefit intensity. In this paper, a $1 \mathrm{~m}$ spatial resolution is assumed, and the published ArcGIS tool (BGC, 2017) resamples any input data to $1 \mathrm{~m}$ resolution before performing the analysis.

\subsection{Producing real benefit curves}

The shape of the benefit curve can be derived from an understanding of how a characteristic benefits or dis-benefits the beneficiaries. Figure 2 shows a benefit curve for pollution by particulate matter of diameter $\leq 10 \mu \mathrm{m}\left(\mathrm{PM}_{10}\right)$. The curve was created using values from the UK's Department for Food Environment and Rural Affairs (Defra) air quality index (AQI) (Ayres, 2011). The AQI score is based on experts' recommendations and ranks air quality on a scale from 1 (low pollution) to 10 (very high pollution). By inverting this scale and stretching it to a $0-10$ scale it can be used as the basis of a benefit curve, and a trend line is fitted to the AQI scale to provide a formula for benefit calculation.

\subsection{Potential benefit}

For each grid square, a benefit uplift of 10 represents a transition from the worst case to the best case. In practice, most locations are not initially in the worst case but are somewhere between best and worst cases. For example, consider a grid square currently rated as $6 \cdot 5 / 10$ and a proposed Suds scheme

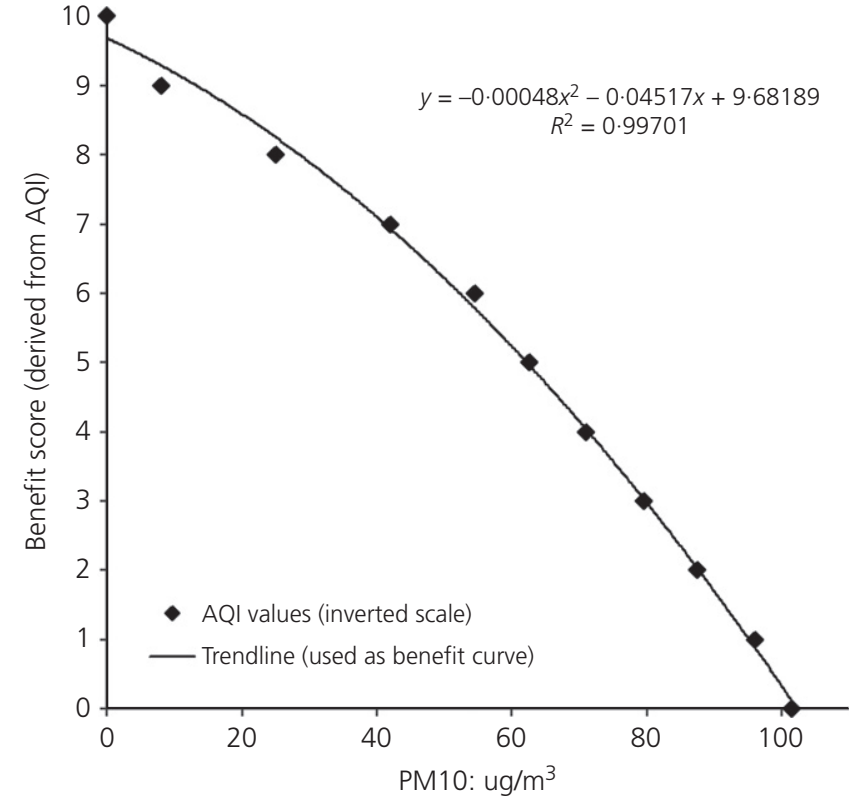

Figure 2. Benefit curve based on air quality index

that improves this score to $9 \cdot 5 / 10$. It may appear that the Suds scheme achieved an incremental benefit uplift of $3 \cdot 0 / 10$. However, this is misleading because the benefit uplift is really a more significant $3.0 / 3.5$ in terms of getting close to the remaining maximum potential benefit possible. Thus, the potential benefit can be defined as the difference between the best case (10) and the before case $\left(b_{\text {bef }}\right)$

1. $P=10-b_{\text {bef }}$ where $0 \leq b_{\text {bef }} \leq 10$

The potential benefit derivation is also shown in Figure 1. With the potential benefit calculated for each grid square, it is possible to produce maps showing where there is the greatest opportunity for improvement. This is demonstrated later in the paper.

\subsection{Multiple-benefit intensity}

Having produced the benefit intensity maps for each benefit category (as separate layers in the GIS tool) it is possible to combine these into a single cumulative multiple-benefit intensity map. This allows the identification of areas where different benefits overlap and the total spatial extent of the benefits of the proposed Suds scheme. As each benefit intensity is scored out of 10, a multiple-benefit intensity map has a maximum value of ten times the number of benefit categories considered. The layers in the multiple-benefit intensity maps can be weighted to give greater importance to certain benefit categories, and this may be done to reflect stakeholders' priorities and local concerns.

\subsection{Benefit profile}

While the benefit intensity maps allow easy identification of the spatial distribution of benefits, it is also useful to present 
the results in graphical form. By summing the benefit uplift from each grid cell in a benefit intensity map, a total benefit score can be derived. An example benefit profile is shown in Figure 3 as a bubble plot. This compares the relative performance of each benefit category in terms of both the magnitude of the benefit achieved and the area over which this benefit has influence. The size of each bubble reflects the extent to which the maximum potential benefit in that category has been realised.

\subsection{Effectiveness}

Finally, the effectiveness can be defined as the ratio between the benefit uplift and the potential benefit

2. $E=\frac{B}{P} \quad$ where $B \geq 0$ and $0 \leq E \leq 1$

In the example given in Section $2.6, \quad E=3 \cdot 0 / 3 \cdot 5 \approx 0 \cdot 86$. Thus, for this grid square, the intervention was highly effective. The objective of a scheme designer will be to minimise the dis-benefits while maximising the benefits. Thus, the effectiveness of a dis-benefit must be judged against the worst case.

3. $E=\frac{B}{10-P} \quad$ where $B<0$ and $-1 \leq E \leq 0$

For example, consider another grid cell initially rated at $9 \cdot 5 / 10$ and rated at $8 \cdot 5 / 10$ after the Suds scheme. The effectiveness in this case would be $E=-1 /(10-0 \cdot 5) \approx-0 \cdot 11$. The effectiveness allows for a simple measure of whether a benefit uplift is significant in the local context and can be calculated for all the grid squares in an area.

\section{Case studies}

To develop and test the new evaluation tool, six benefit categories were evaluated in three case study locations in Newcastle, UK.

\subsection{Case study benefits}

A comprehensive multiple-benefit evaluation would consider as many different benefit categories as possible (including water quantity, water quality and amenity and biodiversity benefits) and then identify a smaller set of the relevant dominant benefits that are important in the location under scrutiny. For the purpose of demonstrating the method, six benefit categories were selected to provide contrasting examples of benefit evaluation. These benefits should not be considered as either inclusive or necessarily representing the most relevant benefits provided by Suds/GI using BGI. They are used here to explore how a range of disparate benefits can accumulate and be distributed spatially. The six benefits considered were
access to green space
- pollutant trapping $\left(\mathrm{PM}_{10}\right)$
- carbon dioxide sequestration
- flood damage avoided
- habitat size and
noise pollution attenuation.

Simple spatial models were developed to provide input data for the benefits evaluation tool, but more refined models could be utilised (as they become available through other research) to refine the procedure. The models described here are intended to demonstrate the principles of benefit evaluation.
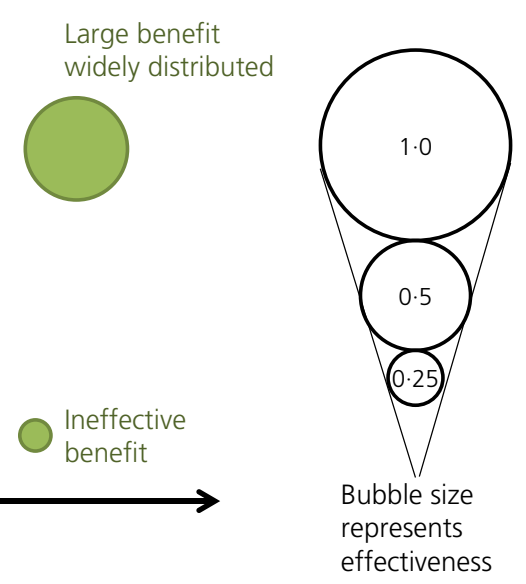

Dis-benefit

Small benefit

locally distributed

Extent of area affected: $\mathrm{m}^{2}$

Ineffective

benefit

represents

effectiveness

Figure 3. Example of a benefit profile 
To evaluate the uplift in benefits attributable to a specific Suds/GI installation it is necessary to establish the initial/preexisting spatial distribution in each benefit category. Many cities now employ models to identify such spatial distributions of pollution, flood damage, access to green space and many more categories that could be affected by the introduction of BGI. Therefore, the starting point, and input data, for the benefit evaluation are raster maps of each benefit category both without the BGI (before) and with the BGI (after). The most common anticipated use of the method is to produce before and after maps for a proposed infrastructure project. For each benefit category the raster maps produced are in relevant units and the resolution is appropriate for that category; for example, flood damage is measured in pounds or dollars while noise is measured in decibels. Further details on each benefit category considered are given in the following sections.

\subsubsection{Access to green space}

Extensively published literature has shown that urban green space has a range of benefits (Chee et al., 2015; Pietilä et al., 2015) and public policy often supports increasing the amount of green space in urban areas. Access to green space is a good example benefit because it is very context-specific: a new area of green space in an area with very little existing green space may have a transformational effect in that location while in another area with plenty of green space the same intervention may convey little or no relative additional benefit at all.

The access to green space tool identifies areas of public green space with data taken from the Ordnance Survey (OS) Mastermap and the road network from the OS integrated transport network (ITN) that may be suitable for walking or recreation. A raster cost-distance calculation is performed twice: once for all areas of green space greater than $500 \mathrm{~m}^{2}$ and once for all areas of green space greater than $50 \mathrm{~m}^{2}$. This is done so that access to smaller areas of green space $\left(50-500 \mathrm{~m}^{2}\right)$ can be screened by a factor of 0.5 in the final calculation. Green space of less than $50 \mathrm{~m}^{2}$ (such as kerbsides) was deemed too small for recreation and excluded from the calculation.

\subsubsection{Pollutant trapping $\left(\mathrm{PM}_{10}\right)$}

The pollutant trapping characteristic represents the dispersion of $\mathrm{PM}_{10}$ pollution from the road network. Three different concentrations of $\mathrm{PM}_{10}\left(30,40\right.$ or $\left.50 \mu \mathrm{g} / \mathrm{m}^{3}\right)$ are distributed depending on the road type (motorway, A road, B road, minor road, local street, private road or alley), with motorways and A roads having higher pollution levels. The pollution is then dispersed in proportion to the distance from the road for each of the three initial concentration levels.

These three pollution distributions are then combined to produce an overall pollution distribution. This allows for a location between a major polluting road and a minor polluting road to have a pollution level that has a contribution from both sources. Different land covers from the OS Mastermap are allocated values based on their ability to reduce or block $\mathrm{PM}_{10}$ (more information is given elsewhere (Diapouli et al., 2008; McDonald et al., 2007; TfL, 2011; Tiwary et al., 2009; Yang et al., 2008)). In general, based on the literature, these range from $0-7 \%$, and these values are used to reduce the pollution concentration in the relevant areas.

\subsubsection{Carbon dioxide sequestration}

The amount of carbon dioxide sequestered is based on the land cover from the OS Mastermap, with each type assigned a sequestration rate ranging from 0 to $180 \mathrm{gCO}_{2} / \mathrm{m}^{2}$ per year (these values were derived from and are consistent with the works of Hunt et al. (2002), Nowak et al. (2013) and Zhu et al. (2012)). Twelve land covers were identified from the Mastermap (e.g. coniferous trees or gardens). Higher sequestration rates are assigned to woodland and lower rates to grassland. Manmade surfaces, except buildings with green roofs, are assigned a 0 score.

\subsubsection{Flood damage avoided}

The flood risk model uses flood depth and extent data from the CityCat Urban Flood Model (2017) developed by researchers at the University of Newcastle. Multiple return periods of $2,10,30,50,100$ and 200 years are considered to find the annualised damage risk. OS Mastermap and building class data are used to identify the different land uses and depth-damage curves to convert flood depths into damage. Different depth-damage curves are used for each of the different land uses in the style of the multi-coloured manual (Penning-Rowsell et al., 2013). The model can thus account for when a small depth of flooding in a built-up area causes significantly more damage than a deep flood in green space.

\subsubsection{Habitat size}

This tool considers the benefit of having larger and connected open green spaces. There is evidence that larger green spaces support more species per square metre than smaller green spaces (Rondinini, 2011; Tjørve et al., 2008). This tool identifies clusters of interconnected green spaces and estimates the number of species supported by each cluster. Thus, large areas are calculated as supporting a species density of around $500 / \mathrm{m}^{2}$ while smaller areas can be as low as $15 / \mathrm{m}^{2}$. Non-green areas are defined as 0 by default.

\subsubsection{Noise pollution attenuation}

The noise pollution model distributes noise from the road network based on road type. Seven different source noise levels are modelled, ranging from $85 \mathrm{~dB}$ to $110 \mathrm{~dB}$. A cost-distance calculation is performed for each noise level to attenuate the noise based on distance, terrain, surface and obstacles. The seven noise distributions are then combined to produce final noise levels. 


\subsection{Case study locations}

The multiple-benefit evaluation was applied to three case studies in the city of Newcastle, UK (Figure 4). Each of the three locations considered represents a different type of urban form and different types of BGI/Suds. The selection of case studies was informed by the Blue-Green Cities consortium and the Newcastle Learning and Action Alliance (LAA) of local stakeholders (O'Donnell, 2016). The LAA was involved in both selecting the general location and developing the detail of the schemes to be evaluated (O'Donnell et al., 2017). Thus, although two of the case studies are hypothetical, they are based on plausible future or current projects. A brief description of each location and the evaluation performed is now given.

\subsubsection{Wingrove}

Wingrove is a residential neighbourhood to the west of the city centre with a population of around 14000 . It is characterised by densely packed terraced houses. A community partnership called Greening Wingrove is promoting a range of green living improvements in the neighbourhood. Two cases were modelled - the current state of the neighbourhood (the before case) and a hypothetical greening, based on the Greening Wingrove project, where all gardens had natural surfaces and small additional green areas were inserted into public areas (the after case). This was done by varying permeabilities in Newcastle University's Citycat model (which hydrodynamically models coupled surface and subsurface flows).

\subsubsection{Urban core}

The urban core represents a hypothetical retrofit in three parts of central Newcastle - the University of Newcastle campus, St James' Boulevard and the main shopping areas. The mix of Suds proposed in each location is different and appropriate to the local context, but includes the addition of permeable paving, swales, street trees and new green space. Two cases were modelled - the current situation (the before case) and a set of hypothetical interventions that were developed in coordination with the Newcastle LAA. These interventions included green roofs, permeable paving, swales and street trees (the after case).

\subsubsection{Newcastle Great Park}

To the north of the city adjacent to the A1, Newcastle Great Park includes pre-existing Suds installations built beside the River Ouseburn. Ponds were created to manage the runoff from an ongoing Newcastle Great Park housing development. To the south of the site are an existing housing estate and a golf club. The total site area is around 50 ha and contains 13 interconnected ponds built between 2005 and 2007. Two cases were modelled - the situation where the ponds and tree planting had not taken place (the before case) and the site in its current state (the after case). Thus, the current benefits of the Suds installation could be ascertained, as opposed to the benefit of Newcastle Great Park without any Suds installations.

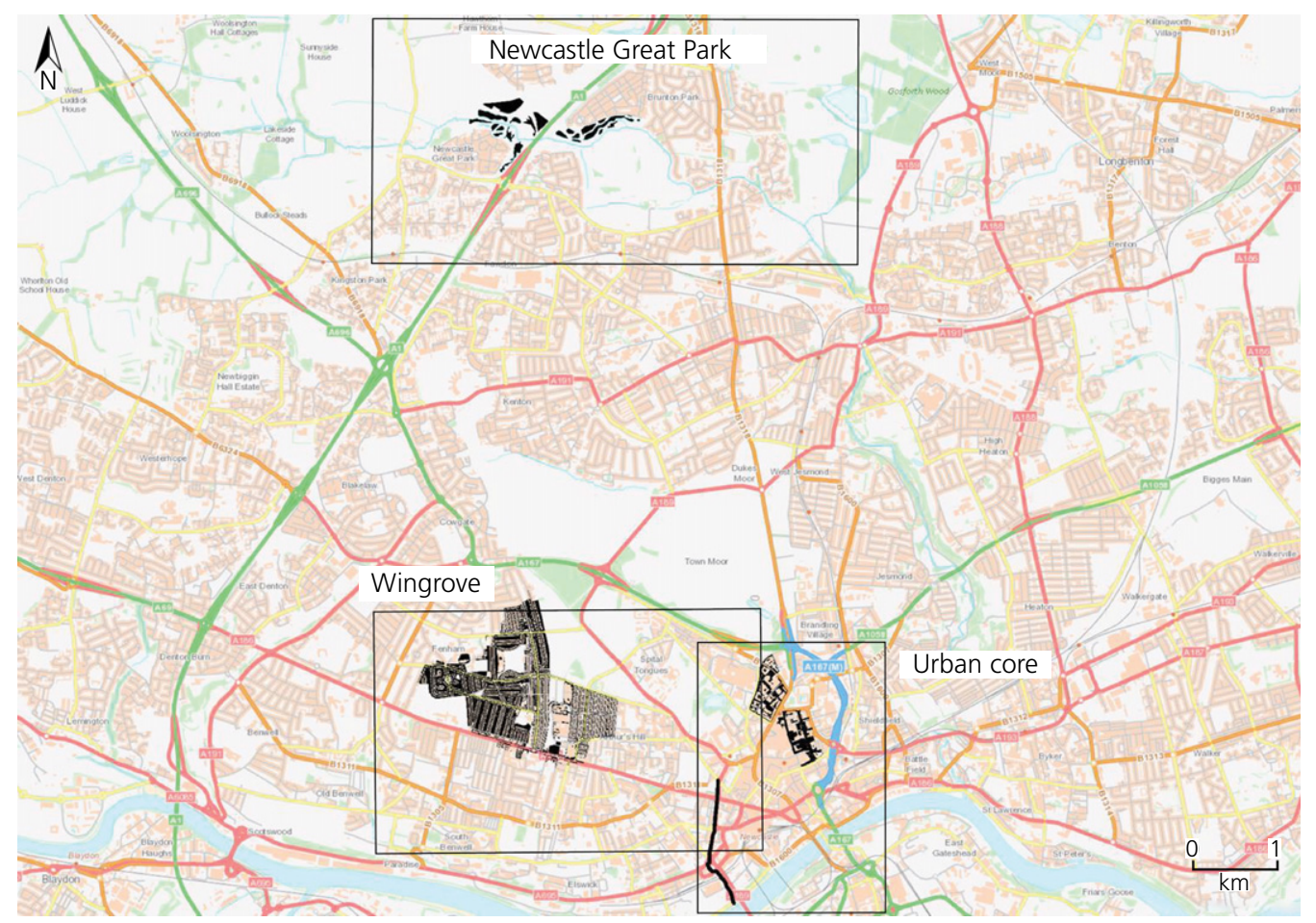

Figure 4. Map of Newcastle and the case study locations. The locations of the BGI and extent of the models are also shown (base map OS Open Carto) 


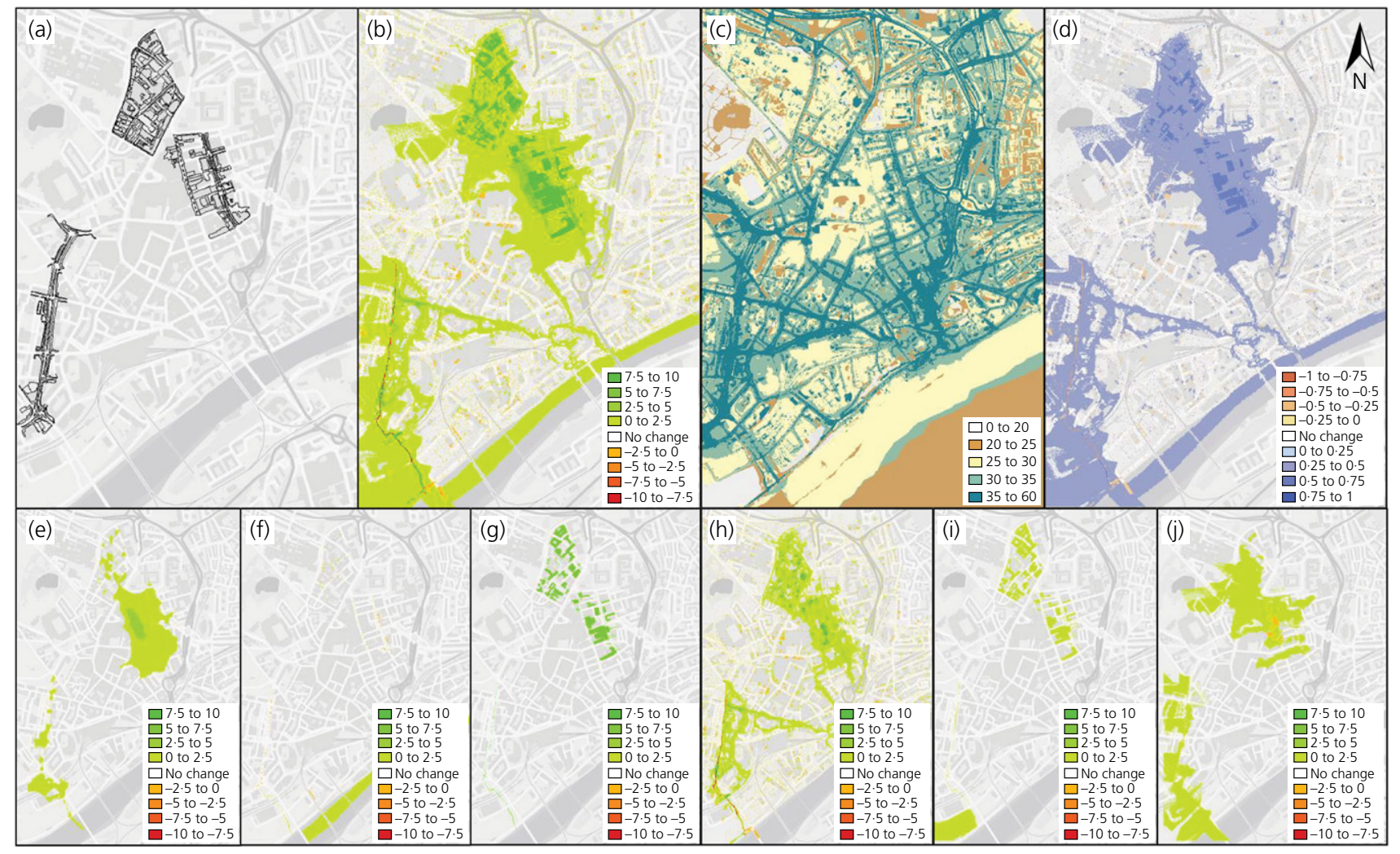

Figure 5. Urban core intensity map results: (a) location of proposed scheme; (b) multiple benefits; (c) multiple potential; (d) multiple effectiveness; (e) access to green space; ( $f$ ) pollutant trapping; (g) carbon sequestration; (h) flood damage avoided; (i) habitat size; (j) noise attenuation

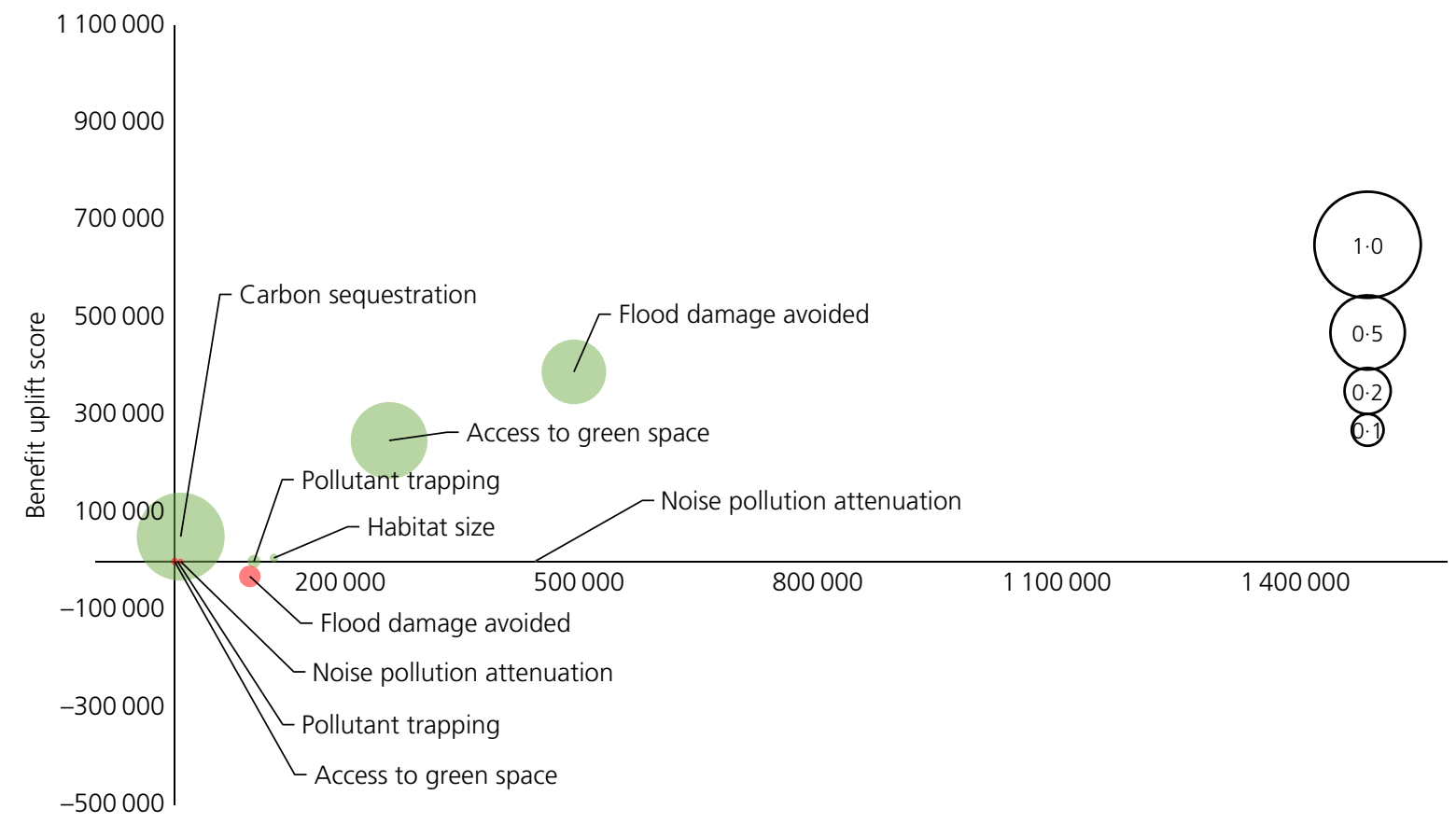

Area: $\mathrm{m}^{2}$

Figure 6. Urban core benefit profile 
Spatial evaluation of the multiple benefits of sustainable drainage systems

Morgan and Fenner

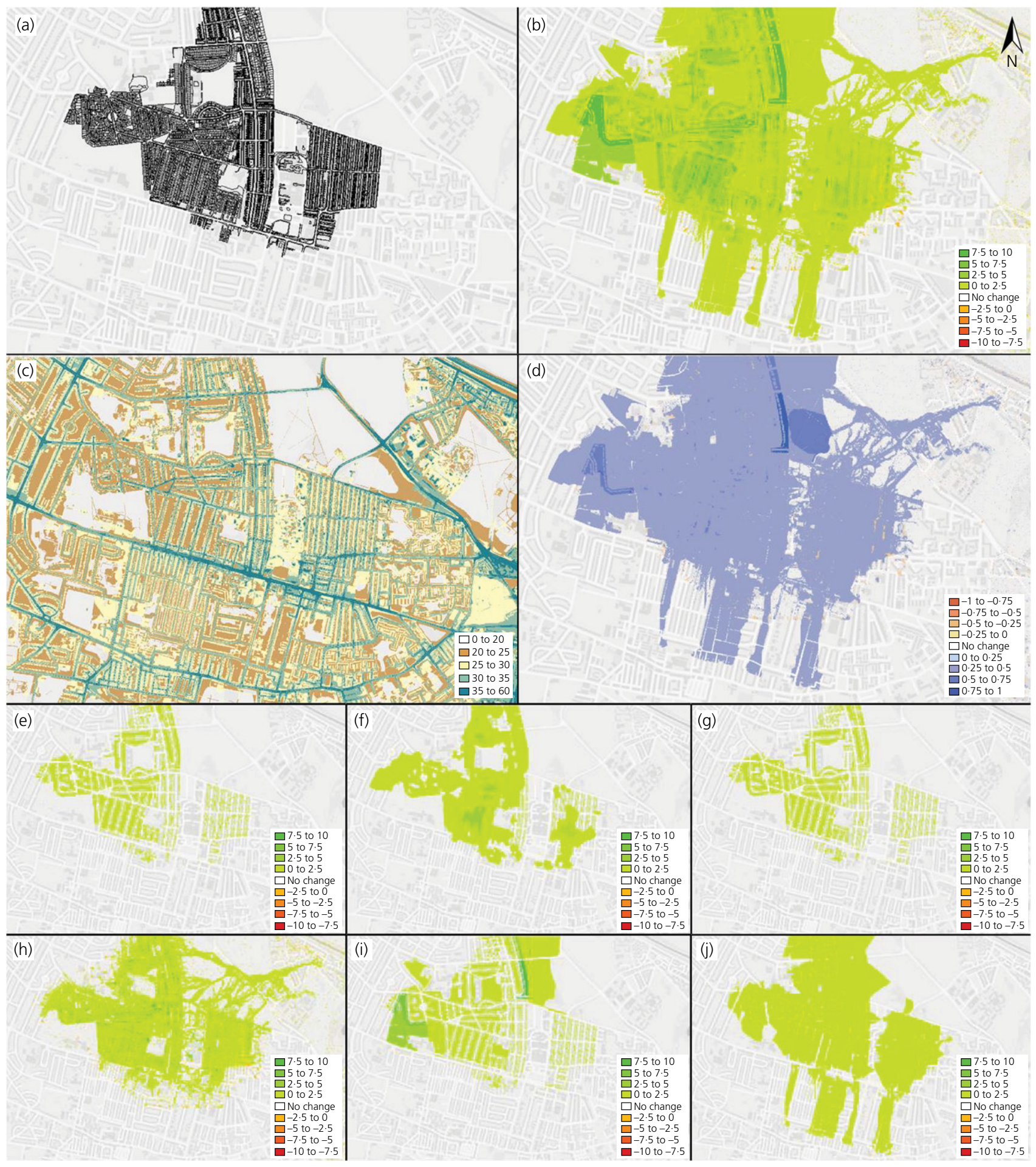

Figure 7. Wingrove intensity map results: (a) location of proposed scheme; (b) multiple benefits; (c) multiple potential; (d) multiple effectiveness; (e) access to green space; (f) pollutant trapping; (g) carbon sequestration; (h) flood damage avoided; (i) habitat size; (j) noise attenuation 


\section{Results}

\subsection{Urban core}

As noted earlier, the proposed interventions included swales, green roofs, tree planting and permeable paving. The spatial distributions of the benefits and the benefit profile are shown in Figures 5 and 6, respectively, with Figure 5(b) representing the overall multiple-benefit intensity. Within the urban core, three benefits dominate: a small but effective increase in carbon dioxide sequestration from the increase in natural surfaces such as green roofs; a moderate increase in access to green space, as green roofs were assumed to be inaccessible and so did not contribute to the access benefit score; and a moderate reduction in flood damage mostly associated with the swale along St James' Boulevard. The minor flood dis-benefit shown in the benefit profile is due to a slight misalignment between the flood modelling and the land use map; this does not reflect an actual increase in flood damage and should be ignored.

\subsection{Wingrove}

The proposed interventions included permeable paving and urban greening replacing existing impermeable paving and paved gardens. The spatial distributions of benefits and the benefit profile are shown in Figures 7 and 8, respectively, with Figure 7(b) representing the overall multiple-benefit intensity. As an area that lacked green space, Wingrove showed significant benefits from the greening programme. Across all the benefits considered (except for pollutant trapping) benefits were observed radiating out from the site and in some cases extending significantly beyond the boundary of the site, including the flood damage avoided. As particulate concentrations were initially low in this area, due to the distance from the major road network, the scope for benefit uplift in the pollutant trapping category was significantly reduced. The benefit profile shows that access to green space and the increase in habitat size were the most significant benefits. The large size of the access to green space bubble also shows that the intervention was effective and achieved a high proportion of the total potential benefits.

\subsection{Newcastle Great Park}

The installed interventions include swales, green roofs, tree planting and permeable paving. Figures 9 and 10 show that very limited multiple benefits were found from the Suds on the Great Park Site in relation to the large areas of existing green space surrounding the site, such that the incremental opportunities for benefits associated with increasing the area of green space were limited. For example, there was no overall change in habitat sizes as a result of the Suds scheme, although the types of habitat changed.

The flood modelling also showed limited flood alleviation benefits, although the modelling did show that the ponds were storing water and reducing flood depths in several locations. It should be noted that the ponds were designed to manage the runoff from the new housing estates to the north and were not explicitly designed in relation to potential downstream flooding.

Some dis-benefits were identified, for example where the change from green space to water resulted in a decrease in carbon

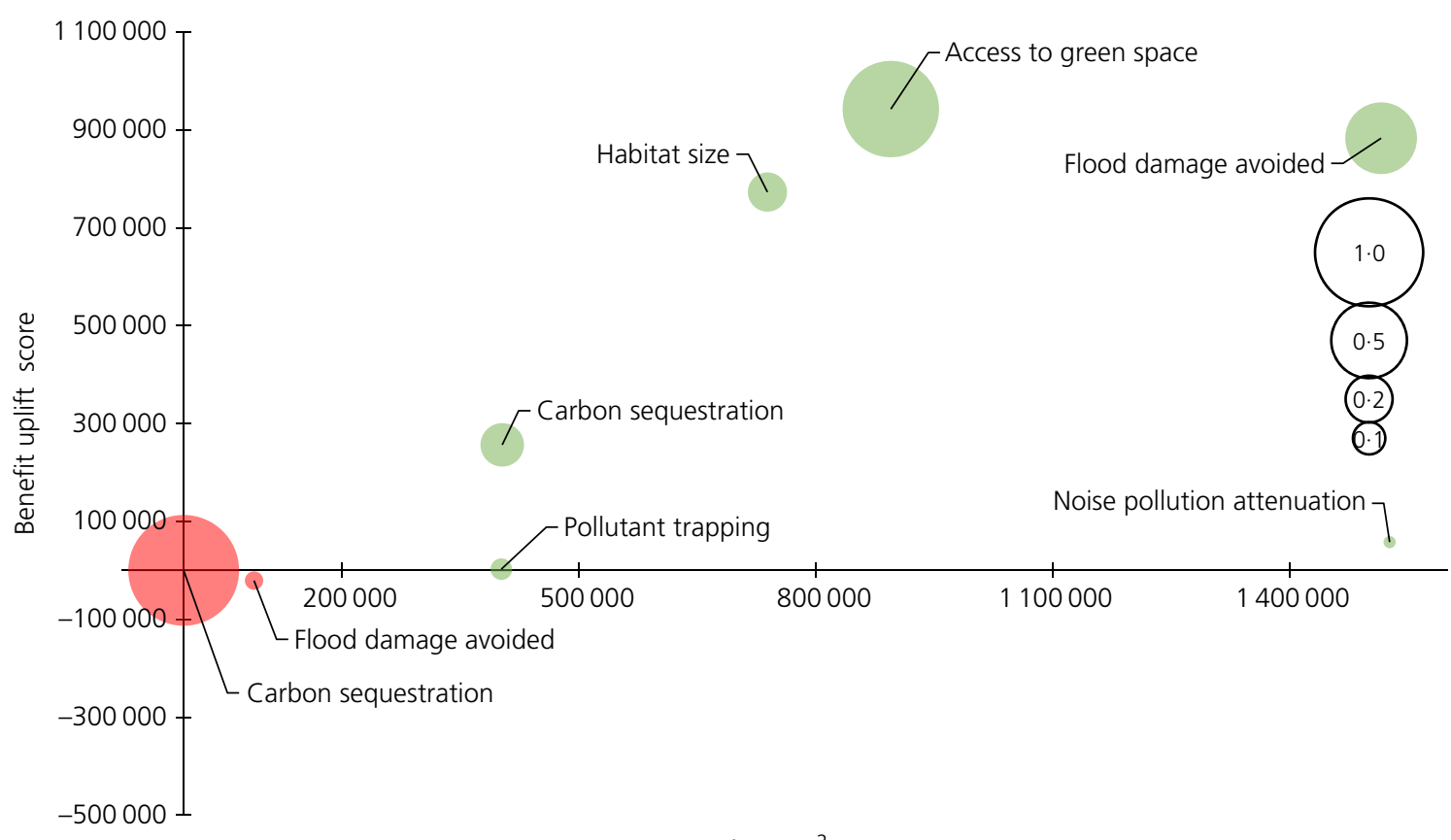

Area: $\mathrm{m}^{2}$

Figure 8. Benefit profile for Wingrove 


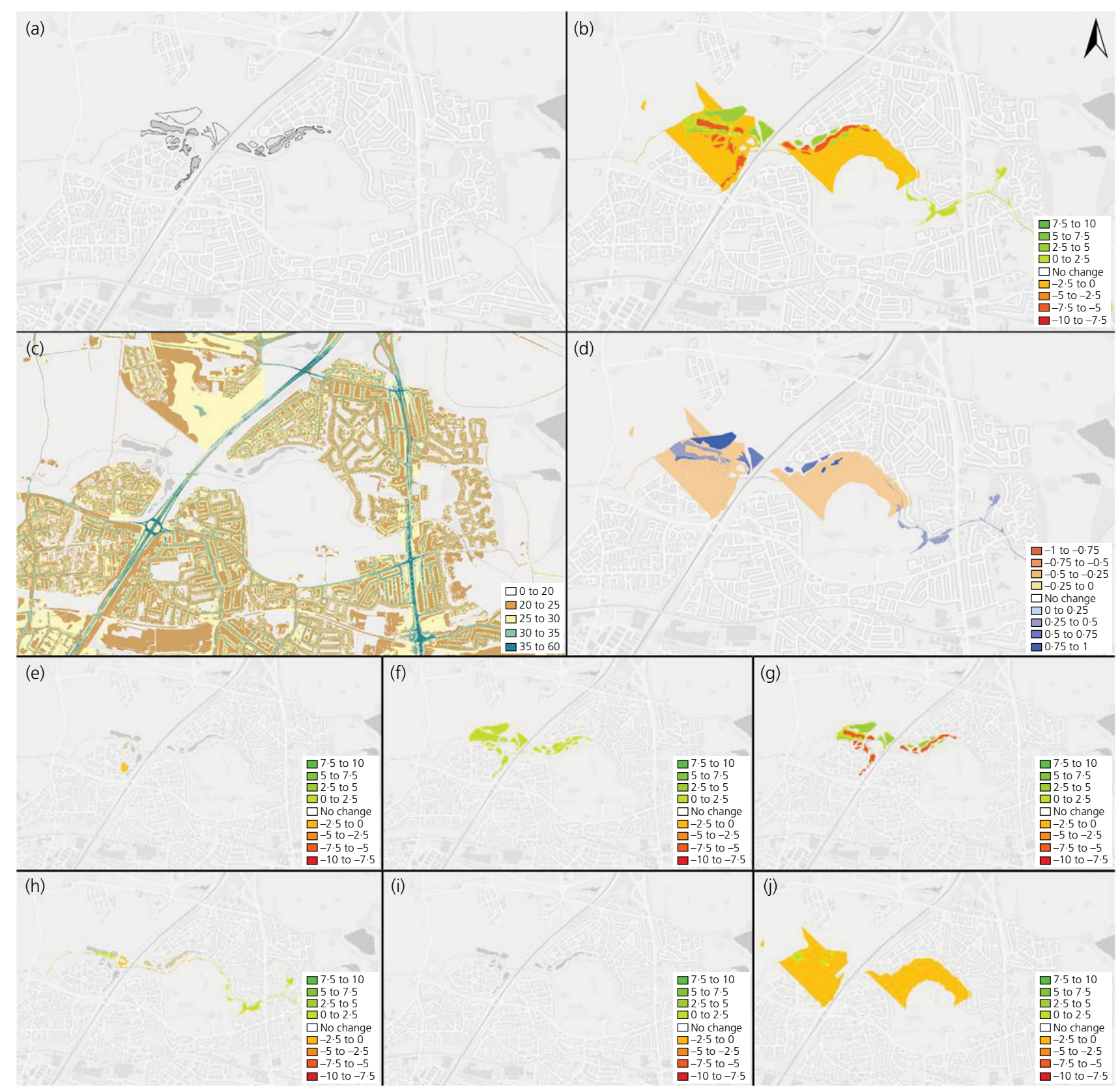

Figure 9. Newcastle Great Park intensity map results: (a) location of proposed scheme; (b) multiple benefits; (c) multiple potential; (d) multiple effectiveness; (e) access to green space; (f) pollutant trapping; (g) carbon sequestration; (h) flood damage avoided; (i) habitat size; (j) noise attenuation

dioxide sequestration; however, this was offset in part by areas of tree planting. In reality, some of the ponds have reeds growing in them and are only filled with water some of the time, so some carbon dioxide sequestration would be expected. The model, however, did not account for these details.

\section{Discussion}

The key features of the preceding analysis are as follows. The results from the case studies show that benefits do not accrue uniformly and that each benefit has a different spatial distribution and may accrue to different stakeholder groups than the asset owner. It would be possible to incorporate a 'beneficiary distribution' as a further GIS layer based on population densities to determine the extent that humans are impacted by the benefit distribution, although this has not yet been done. However, this would give the analysis a strongly anthropocentric bias, ignoring the importance of the many benefits that accrue (to wildlife, habitat etc.) even if there are no people in 


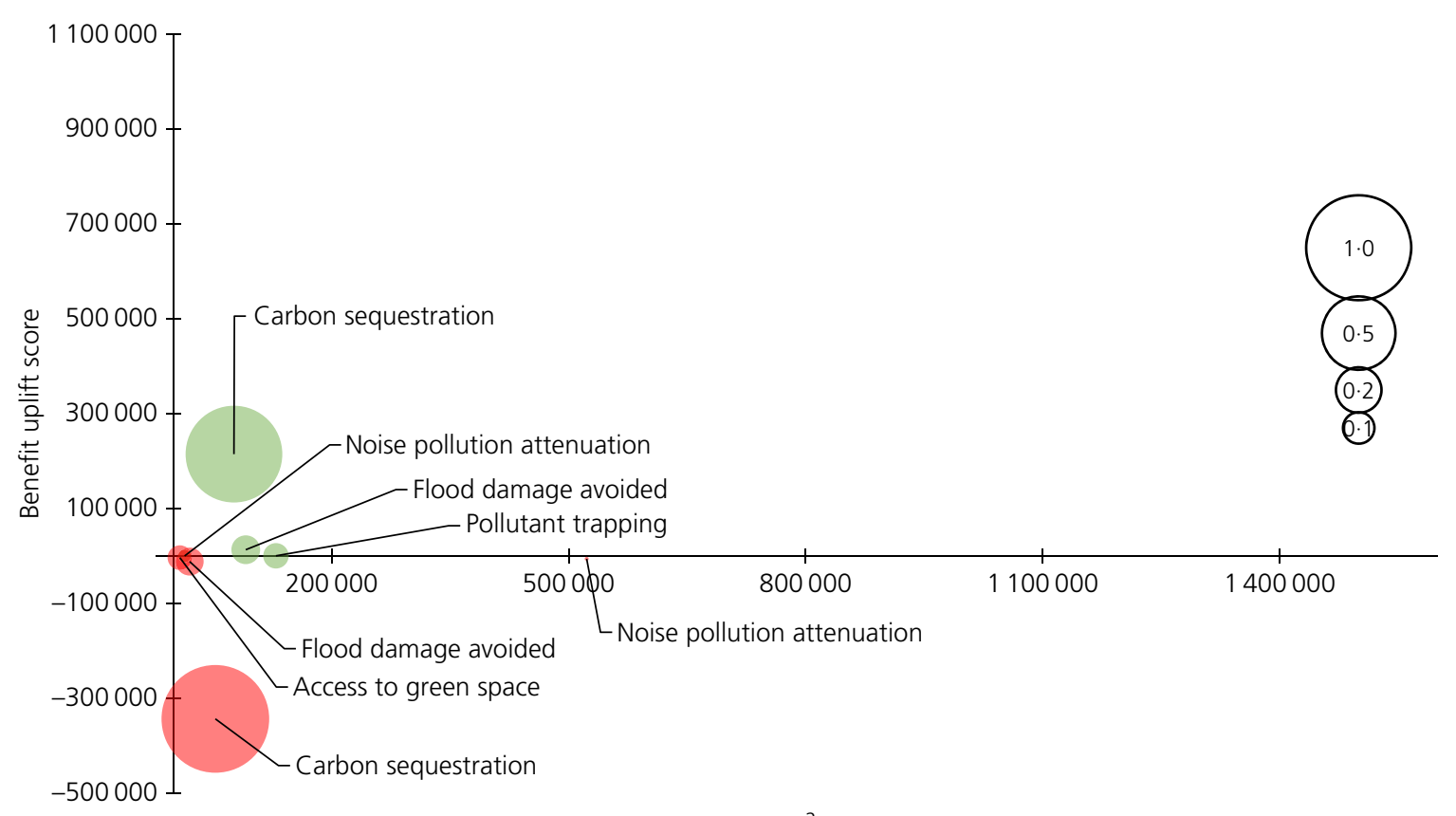

Area: $m^{2}$

Figure 10. Benefit profile for Newcastle Great Park

the area. Population distribution based on housing density can also be misleading. For example, nobody lives in the park but there is a benefit to both people and wildlife from reduced noise in the park.

The benefit intensity maps highlight that benefits do not radiate uniformly but are affected by the urban form. The models used in this study were relatively simple but could be replaced by more refined techniques that have the potential to amplify these spatial variations. Such visual representation can help link the benefits arising from Suds/GI interventions with wider urban planning considerations, beyond simply their urban drainage function.

The benefits evaluation recognises the existing context of the location and the specific prevailing background environmental conditions. Thus, the same intervention in two different locations may have different results. The potential intensity maps reveal those areas that initially have no or low levels of each benefit, and hence where a blue-green intervention could generate the greatest improvement. However, in the case studies, the locations where the greatest potential for multiplebenefit uplift was identified did not overlap well with the location of the proposed BGI, driven primarily to satisfy an urban drainage function. Producing potential intensity maps early on in the planning process may help achieve wider outcomes by co-optimising Suds/GI practices with more extensive urban greening. However, it should also be noted that often there is sometimes an opportunistic aspect to decisions about scheme location. For example, the decision to develop improvements on the Newcastle University campus, despite it being an area of low potential to improve benefits beyond those that already exist, was partially based on the University having a willingness to embrace BGI on the campus.

The normalisation process is a significant component of the multiple-benefit evaluation, allowing the different natures of wide ranging types of benefits to be compared on a common basis. The precise shape of the benefit curve is central to the effective evaluation of benefits. This task is independent of the modelling of the characteristic of interest in a particular location and such curves could be standardised for all evaluations. Comparing different benefits in this way can lead to the identification of the small number of relevant dominant benefits in a given location. Specific engineering designs and choices of types of Suds assets can thus be informed so this subset of benefits can be co-optimised with the drainage and flood protection function.

Following a basic benefit evaluation as described in this paper, it is a simple step to weight the different benefit categories on the basis of stakeholder preferences following a systematic survey of the communities and users affected by the proposals. This modification to the neutrally weighted analysis could help confirm and refine which of the dominant benefits are seen as relevant and important to be optimised through initial design modifications and subsequent maintenance and management strategies. 
The success of the method is ultimately dependent on the quality of the modelling. Detailed urban models are becoming increasingly common, so benefit intensities and benefit profiles may be straightforward to produce in the future. These are most useful in the early stages of design, to examine the selection of the location of a scheme and for option testing. With the necessary data available, a full multiple-benefit evaluation for a location can be performed on a desktop computer in a few hours by one person. It is thus reasonable to run many permutations, including direct comparisons with the benefits that arise from conventional grey infrastructure solutions.

\section{Conclusion}

Evaluating the spatial distribution of Suds benefits provides an added dimension in the assessment of existing and proposed urban drainage assets, which can be used alongside other approaches such as Ciria's BeST tool (Ciria, 2015). It is clear that by considering the cumulative effect of multiple benefits from blue-green installations, both in terms of monetising the value they can achieve and understanding how they have the potential to trigger widespread gains across urban environments, a stronger case can be made for their adoption. Through better integration in the wider planning process, future uses of Suds will not only tackle the challenges of expected increases in stormwater runoff but will also be a significant feature in the evolution of sustainable cities.

\section{Acknowledgements}

This research was performed as part of an interdisciplinary project programme undertaken by the Blue-Green Cities (BGC) Research Consortium (BGC, 2017). The BGC Consortium is funded by the UK Engineering and Physical Sciences Research Council under grant EP/K01366 1/1, with additional contributions from the Environment Agency and Rivers Agency (Northern Ireland) and National Science Foundation. Associated research data can be downloaded from http://dx.doi.org/10.17639/nott.59.

\section{REFERENCES}

Ahilan S, Wright N, Sleigh A et al. (2014). Flood risk management in small urban river using a sustainable urban drainage system: Wortley Beck, Leeds, UK. Proceedings of International Conference on Hydroinformatics (HIC 2014), New York, NY, USA. Cuny Academic Works, New York, NY, USA.

Ashley RM, Lundy L, Ward S et al. (2013) Water-sensitive urban design: opportunities for the UK. Proceedings of the Institution of Civil Engineers - Municipal Engineer 166(2): 65-76, http://dx.doi.org/ 10.1680/muen.12.00046.

Ayres JG (2011) Review of the UK Air Quality Index: A Report by the Committee on the Medical Effects of Air Pollutants. https://www.gov.uk/government/uploads/system/uploads/ attachment_data/file/304633/COMEAP_review_of_the_uk_air_ quality_index.pdf (accessed 06/05/2016).

Benedict MA and McMahon ET (2012) Green Infrastructure: Linking Landscapes and Communities. Island Press, Washington, DC, USA.
BGC (Blue-Green Cities) (2017) http://www.bluegreencities.ac.uk (accessed 13/05/2017).

Cabinet Office and New Economics Foundation (2012) A Guide to Social Return on Investment, Cabinet Office and New Economics Foundation. Cabinet Office and New Economics Foundation, London, UK.

Casal-Campos A, Fu G and Butler D (2013) The whole life carbon dioxide footprint of green infrastructure: a call for integration. Proceedings of Novatech 2013. GRAIE, Lyon, France. See http://documents.irevues.inist.fr/handle/2042/51257 (accessed 05/06/2017).

Chee A, Lee K, Jordan HC and Horsley J (2015). Value of urban green spaces in promoting healthy living and wellbeing: prospects for planning. Risk Management and Health Care Policy 8: 131-137, http://dx.doi.org/10.2147/RMHP.S61654.

Ciria (2013) Research Project RP993 Demonstrating the Multiple Benefits of Suds - A Business Case (Phase 2) Draft Literature Review. Ciria, London, UK. See http://www.susdrain.org/files/ resources/ciria_guidance/ciria_rp993_literature_review_october_ 2013_.pdf (accessed 19/04/2016).

Ciria (2015) RP 993: Demonstrating the Multiple, Benefits of Suds -A Business Case. Ciria, London, UK. See http://www.susdrain.org/ resources/best.html (accessed 25/05/2016).

CityCat Urban Flood Model (2017) http://www.ncl.ac.uk/ceser/research/ integrated-systems/cities/citycat/ (accessed 05/06/2017).

Demuzere M, Orru K, Heidrich $\mathrm{O}$ et al. (2014) Mitigating and adapting to climate change: multi-functional and multi-scale assessment of green infrastructure. Journal of Environmental Management 146: 107-115, https://doi.org/10.1016/j.jenvman.2014.07.025.

Diapouli E, Grivas G, Chaloulakou A and Spyrellis N (2008) PM10 and ultrafine particles counts in-vehicle and on-road in the Athens area. Water, Air, \& Soil Pollution: Focus 8(1): 89-97.

Dobbs C, Kendal D and Nitschke CR (2014) Multiple ecosystem services and disservices of the urban forest establishing their connections with landscape structure and sociodemographics. Ecological Indicators 43: 44-55, http://dx.doi.org/10.1016/j.ecolind.2014.02.007.

Ellis JB (2013) Sustainable surface water management and green infrastructure in UK urban catchment planning. Journal of Environmental Planning and Management 56(1): 24-41.

Flynn KM and Traver RG (2013) Green infrastructure life cycle assessment: a bio-infiltration case study. Ecological Engineering 55: 9-22, http://dx.doi.org/10.1016/j.ecoleng.2013.01.004.

Hilde T and Paterson R (2014) Integrating ecosystem services analysis into scenario planning practice: accounting for street tree benefits with i-Tree valuation in Central Texas. Journal of Environmental Management 146: 524-534, http://dx.doi.org/10.1016/j.jenvman. 2014.05.039.

Hoang $L$ and Fenner RA (2016) System interactions of flood risk strategies using sustainable urban drainage systems and green infrastructure. Urban Water Journal 13(7): 739-758.

Hoang L, Fenner RA and Skenderian M (2016) A conceptual approach for evaluating the multiple benefits of urban flood management practices. Journal of Flood Risk Management.

Hunt ER Jr, Fahnestock JT, Kelly RD et al. (2002) Carbon sequestration from remotely sensed NDVI and net ecosystem exchange. In From Laboratory Spectroscopy to Remotely Sensed Spectra of Terrestrial Ecosystems (Muttiah RS (ed.)). Kluwer, Dordrecht, the Netherlands, pp. 161-174.

Jayasooriya VM and Ng AWM (2014) Tools for modelling of urban flood management and economics of green infrastructure practices: a review. Water, Air, \& Soil Pollution 225(8): 2055.

Jose R, Wade R and Jefferies C (2015) Smart Suds: recognizing the multiple-benefit potential of sustainable surface water management systems. Water Science \& Technology 71(2): 245-251. 
Kim G, Miller PA and Nowak DJ (2015) Assessing urban vacant land ecosystem services: urban vacant land as green infrastructure in the City of Roanoke, Virginia. Urban Forestry \& Urban Greening 14(3): 519-526.

Kopperoinen L, Itkonen P and Niemelä J (2014) Using expert knowledge in combining green infrastructure and ecosystem services in land use planning: an insight into a new place-based methodology. Landscape Ecology 29(8): 1361-1375.

Lauf S, Haase D and Kleinshmit B (2014) Linkages between ecosystem services provisioning, urban growth and shrinkage - a modelling approach assessing ecosystem service trade-offs. Ecological Indicators 42: 73-74, http://dx.doi.org10.1016/j.ecolind2014.01.028.

McDonald AG, Bealey WJ, Fowler D et al. (2007) Quantifying the effect of urban tree planting on concentrations and depositions of PM10 in two UK conurbations. Atmospheric Environment 41(38): 8455-8467.

Natural England (2009) Green Infrastructure Guidance. Natural England, York, UK, NE176.

Natural England (2013) Green Infrastructure Valuation Tools Assessment. Natural England, York, UK, NECR126.

Nowak DJ, Greenfield EJ, Hoehn RE and Lapoint E (2013) Carbon storage and sequestration by trees in urban and community areas of the United States. Environmental Pollution 178: 229-236, http://dx.doi.org/10.1016/j.envpol.2013.03.019.

O'Donnell E (2016) Learning and action alliances: frameworks for developing Blue-Green visions for urban flood risk management. Proceedings of Sniffer Flood Risk Management Conference 2016, Blue-Green Cities Session Day 2, Edinburgh, UK. See http://www.bluegreencities.ac.uk/documents/sniffer2016-bgceodonnell.pdf (accessed 05/06/2017).

O'Donnell E, Woodhouse R and Thorne C (2017) Evaluating the multiple benefits of a Newcastle surface water management scheme. Proceedings of the Institution of Civil Engineers - Water Management, http://dx.doi.org/10.1680/jwama.16.00103.

Pennig S and Schady A (2014) Railway noise annoyance: exposureresponse relationships and testing a theoretical model by structural equation analysis. Noise and Health 16(73): 388-399.

Penning Rowsell E, Tapsell S, Johnson C and Wilson T (2005) Development of Economic Appraisal Methods for Flood Management and Coastal Erosion Protection Joint DefralEA Flood and Coastal Erosion Risk Management R\&D Programme. See http://evidence. environment-agency.gov.uk/FCERM/Libraries/FCERM_Project Documents/FD2014_3861_TRP_pdf.sflb.ashx.

Penning-Rowsell E, Priest S, Parker D et al. (2013) Flood and Coastal Erosion Risk Management: A Manual for Economic Appraisal (Multi-Coloured Manual 2013). Routledge.

Pickard BR, Daniel J, Mehaffey M, Jackson LE and Neale A (2015) EnviroAtlas: A new geospatial tool to foster ecosystem services science and resource management. Ecosystem Services 14: 45-55, http://dx.doi.org/10.1016/j.ecoser.2015.04.005.

Pietilä M, Neuvonen M, Borodulin K and Tyrvainen L (2015) Relationships between exposure to urban green spaces, physical activity and self-rated health. Journal of Outdoor Recreation and Tourism 10: 44-54, http://dx.doi.org/10.1016/j. jort.2015.06.006

Rondinini C (2011) Meeting the MPA Network Design Principles of Representativity and Adequacy: Developing Species-Area Curves for Habitats. JNCC Committee Report 439.

Spengenberg J and Settele J (2010) Precisely incorrect? Monetising the value of ecosystem services. Ecological Complexity 7: 327-337, https://doi.org/10.1016/j.ecocom.2010.04.007.

Sukhdev P, Wittmer H, Schröter-Schlaack C et al. (2010) The Economics of Ecosystems and Biodiversity: Mainstreaming the Economics of Nature: A Synthesis of the Approach, Conclusions and Recommendations of TEEB. TEEB Team, United Nations Environment Programme for the European Commission,
Geneva, Switzerland. See http://www.teebweb.org/publication/ mainstreaming-the-economics-of-nature-a-synthesis-of-theapproach-conclusions-and-recommendations-of-teeb/ (accessed 05/06/2017)

TfL (Transport for London) (2011) What is Air Quality on the Road Network and How Does This Vary by Road Type, Location and Time of Day? TfL, London, UK, Roads Task Force Technical Note 21

Tjørve E, Kunin WE, Polce C and Calf Tjørve KM (2008) Species-area relationship: separating the effects of species abundance and spatial distribution. Journal of Ecology 96(6): 1141-1151.

Turner KG, Odgaard MV, Bocher PK, Dalgaar T and Svenning JC (2014) Bundling ecosystem services in Denmark: trade-offs and synergies is a cultural landscape. Landscape and Urban Planning 125: 89-104, https://doi.org/10.1016/j.landurbplan.2014.02.007.

Tiwary A, Sinnett D, Peachey C et al. (2009) An integrated tool to assess the role of new planting in PM10 capture and the human health benefits: a case study in London. Environmental Pollution 157: 2645-2653, https://doi.org/10.1016/j.envpol.2009.05.005. UKWP (UK Water Partnership) (2015) Droughts and Floods: Towards $A$ More Holistic Approach. UK Water Partnership Research and Innovation Group, London, UK.

USEPA (US Environmental Protection Agency) (2013) Case Studies Analyzing the Economic Benefits of Low Impact Development and Green Infrastructure Programs. US Environmental Protection Agency, Office of Wetlands, Oceans and Watersheds, Washington, DC, USA. EPA 841-R-13-004.

von Döhren P and Haase D (2015) Ecosystem disservices research: a review of the state of the art with a focus on cities. Ecological Indicators 52: 490-497, https://doi.org/10.1016/j.ecolind.2014.12. 027.

Yang J, Yu Q and Gong P (2008) Quantifying air pollution removal by green roofs in Chicago. Atmospheric Environment 42: 7266-7273, http://dx.doi.org/10.1016/j.atmosenv.2008.07.003.

Zhu Z, Sleeter BM, Griffith GE et al. (2012) An assessment of carbon sequestration in ecosystems of the Western United States - scope, methodology, and geography. In Baseline and Projected Future Carbon Storage and Greenhouse-Gas Fluxes in Ecosystems of the Western United States (Zhu Z and Reed BC (eds)). Department of the Interior, Washington, DC, USA, US Geological Survey Professional Paper 1797, Chapter 1.

\section{How can you contribute?}

To discuss this paper, please email up to 500 words to the editor at journals@ice.org.uk. Your contribution will be forwarded to the author(s) for a reply and, if considered appropriate by the editorial board, it will be published as discussion in a future issue of the journal.

Proceedings journals rely entirely on contributions from the civil engineering profession (and allied disciplines). Information about how to submit your paper online is available at www.icevirtuallibrary.com/page/authors, where you will also find detailed author guidelines 